\title{
Electrical Methods for Diamond-Die Production
}

\section{By Chauncey G. Peters, Walter B. Emerson, Karl F. Nefflen, Forest K. Harris, and Irvin L. Cooter}

\begin{abstract}
Electrical methods to drill diamond have been developed and applied to the making of diamond wire-drawing dies 0.0005 to 0.0015 of an inch in diameter that heretofore were produced solely by mechanical operations. The time required to produce excellent dies is reduced materially by applying these electrical methods to the following operations: 1, Pilot drilling the primary cone with a high-voltage spark in air; 2, drilling the secondary cone with a low-voltage spark in an electrolyte.

These two methods of drilling are described and their application to the making of small dies at the National Bureau of Standards is given in detail.
\end{abstract}

\section{Introduction}

In recent years there has been a remarkable increase in the use of diamond for industrial purposes. About 10 percent of the available supply of industrial diamonds is now required to produce diamond dies for drawing fine wire of uniform diameter.

The following statement is quoted from an article by Paul L. Herz, "Diamonds in the wiredrawing industry": ${ }^{1}$

Up to 50 years ago steel drawplates or ruby or sapphire dies were used for drawing fine wire, and it was necessary to draw the wire slowly. Because the die wore rapidly, increasing the size of the hole, it was difficult to produce accurately gaged wire. In later years dies of tungsten, molybdenum, or boron carbide have competed with diamond dies. Diamonds, however, enjoy an exclusive field for the harder and tougher wire materials, such as chromenickel resistance wire, brass and phosphor bronze wire, and high-carbon steel wire. Diamond is also used for drawing electrolytic copper wire from the smallest sizes up to diameters approaching $0.080 \mathrm{in}$. In addition, diamond is indispensable whenever precision of size and perfect roundness are essential considerations.

Previous to the cutting off of imports from Europe when France and the Low Countries were invaded in 1940, all small diamond dies were imported because labor costs made their manufacture in this country unprofitable. At the request of the War Production Board in January 1943, the

${ }^{1}$ Paul L. Herz, Diamonds in the wire-drawing industry, Am. Mineral. 27, p. 171 to 175 (1942).
National Bureau of Standards undertook an investigation to improve the manufacturing processes and the quality of diamond dies 0.002 to $0.0005 \mathrm{in}$. in diameter in order to meet the requirements for many vital war products. This work was carried on as a joint investigation by the Miscellaneous Minerals Division of the War Production Board and the National Bureau of Standards until July 1, 1943, when administration of the investigation was transferred to the War Metallurgy Committee of the National Research Council.

A diamond die laboratory was installed at the National Bureau of Standards with equipment for studying and testing existing die-drilling and wiredrawing machines and processes, and for developing new methods and new equipment to meet the designated aims of the investigation, namely: (a) to reduce production time and cost, (b) to improve the quality of domestic dies. By the introduction of electrical methods of drilling, both objectives were attained so successfully that users of small-size dies are no longer dependent on foreign importations.

The present paper, superseding the Bureau's final report, Investigation of Small Diamond Dies, NRC-535, Serial No. W-144, September 21, 1944, isued to the War Metallurgy Committee of the National Research Council, includes new developments made at the National Bureau of Standards after the termination on July 1, 1944, 
of the die investigation as a joint project with the War Production Board and the National Research Council.

\section{Description of Small Diamond Dies}

Diamonds weighing one-sixth to one-fourth carat, free from flaws and inclusions, and of symmetrical shape are selected for making small dies, i. e., dies of less than 0.002 in. in diameter. The top and bottom surfaces are made plane and parallel, and a side facet is cut perpendicular to these surfaces to serve as a window through which the profile of the die and the progress of drilling may be observed.

The shape of a wire die is governed by the work it is required to perform. Figure $1 \mathrm{~A}$, shows the customary profile, together with the necessary elements comprising a satisfactory die for drawing

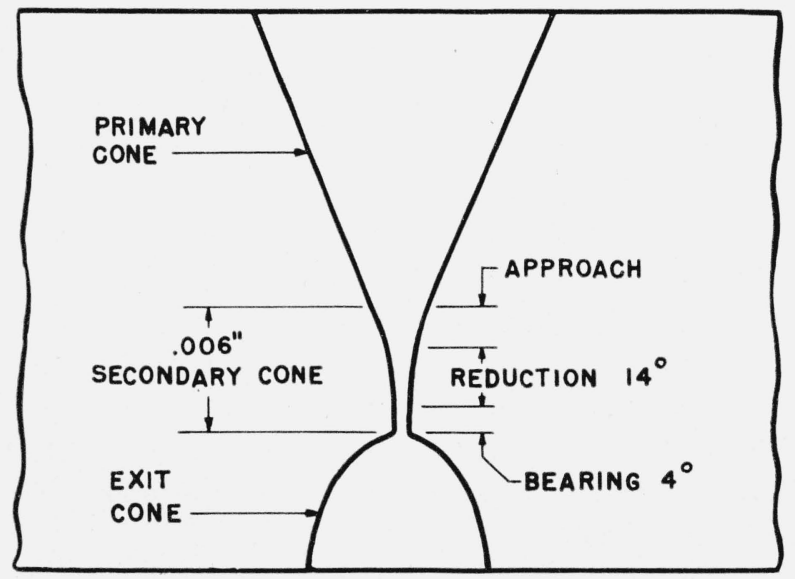

A

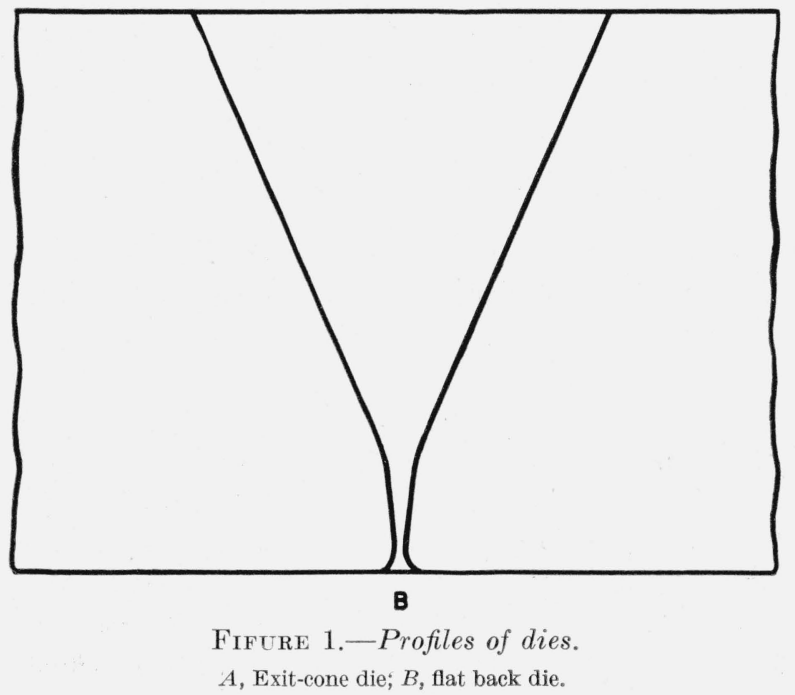

resistance alloy and steel wires. The shape of primary, approach, and exist cones are of secondary importance to the actual working parts of the die, i. e., the reduction and bearing cones, which should be properly shaped and highly polished. A slight rounding-off, or relief, of the bearing cone at its junction with the exit cone, when present, tends to reduce chipping of the diamond during the wire-drawing operation.

Examination of many used dies, however, indicated failure by chipping at the intersection of the bearing and exit cones. This was ascribed to strain and minute fractures in the diamond introduced by the mechanical operations used in forming the exit cone. Figure 1, B, shows the profile of dies produced at the National Bureau of Standards, in which the exit cone is eliminated by lengthening the primary cone and having the secondary cone pierce the relatively unstrained back surface produced by means of a rotating cast-iron lap, with fine diamond powder as an abrasive.

\section{Mechanical Drilling of Dies}

\section{Mechanical Method}

Methods and equipment developed in Europe for drilling diamond dies employ essentially a star drilling action. The drilling machine has a single horizontal spindle that rotates a sharpened steel sewing needle at high speed. The diamond is mounted in a holder that rests on rollers and is free to move back and forth parallel to the axis of the drilling needle. Drilling is accomplished by oscillating the diamond against the rapidly rotating needle. Diamond powder of different grades mixed with oil is used as the abrasive.

Domestic machines operate on the same principle as the European design but usually have 10 vertical spindles.

The following operations are required to drill a die by the mechanical method:

Spotting.-The blank is mounted and centered in a metal disk that is rotated in a bench lathe. A small hole is started in one of the flat surfaces of the stone with a diamond chip held in a pair of pliers. This operation is designated by makers of diamond tools as "bruting." 'The cavity thus formed serves as a starting hole for the drill.

Drilling the primary cone.-A steel needle about $0.040 \mathrm{in}$. in diameter and with a rather blunt 
point is used to drill the primary cone. Relatively coarse diamond abrasive powder is used at the start to speed up the coning operation. Finer powder is substituted as the cone nears completion.

Drilling the secondary cone.-A lighter drilling machine with a fine needle ground to the approximate shape of the desired cone is used to produce the secondary cone. As the drilling proceeds, the needle must be recharged with the required size powder, reground as it wears, and reshaped to give the desired profile to the die. Drilling of the secondary cone is a tedious and timeconsuming operation because of the necessarily small size of abrasive particles, needle diameters, and pressures on the needle that can be used.

Back opening.-After completing the fine drilling, the die is returned to the bench lathe for counter drilling. A spherical hole in line with the die axis is bruted into the back surface of the die with diamond chips held in sharp-nosed pliers until it reaches the secondary cone. In some shops bruting is discontinued when the sphere is within $0.003 \mathrm{in}$. of the cone. The final opening is then made on the drilling machine with a relatively blunt needle.

Polishing.-The polishing operation, performed on a polishing machine, is designed to smooth out any rings formed during the drilling, to smooth the ragged edges where the needle broke through from the back, and to give a fine polish to the working parts of the die.

\section{Drilling Time}

The following time data for these drilling operations for 0.0007 - to 0.0010 -in. dies were obtained from foreign reports and from experience gained in the Bureau's Interferometry Section with similar equipment:

\begin{tabular}{|c|c|c|c|}
\hline & \multicolumn{3}{|c|}{ Time required } \\
\hline & Holland & England & NBS \\
\hline Primary cone $\ldots . . .$. & $\begin{array}{l}h r \\
15\end{array}$ & $\begin{array}{l}h r \\
50\end{array}$ & 12 to 26 \\
\hline $\begin{array}{l}\text { Se con d a r y -cone } \\
\text { drilling }\end{array}$ & 75 & 120 & 80 to 100 \\
\hline Back opening _.... & 6 & $\ldots$ & 8 \\
\hline Polishing $\ldots \ldots \ldots$ & 15 & $\ldots$ & 20 \\
\hline
\end{tabular}

Improved machinery and drilling technics enable American die makers to reduce appreciably the time formerly required to rough-drill the primary cone.

A more detailed description of the mechanical method of making dies, together with illustrations of the required machinery, is given by Grodzinski. ${ }^{2}$

\section{Introduction of Electrical Drilling to Die Making}

A study of the operations involved in making dies by customary mechanical methods indicated that (1) improvement in the quality of a die could be expected from more painstaking attention to details of shape and finish, and (2) no great reduction in manufacturing time could be expected unless radical improvements or innovations could be evolved.

In 1899 Wehnelt ${ }^{3}$ found that by applying voltage to a circuit containing two electrodes, one of which dipped slightly and the other more deeply below the surface of an electrolyte, sparking occurred at the point of the first electrode, causing rapid interruptions of the current. This circuit became known as the Wehnelt electrolytic interrupter. Dawihl and Fritsch, ${ }^{4}$ using this electrolytic method to obtain high frequencies, produced hemispherical holes about $0.30 \mathrm{~mm}$ in diameter and $0.25 \mathrm{~mm}$ deep in the surface of diamonds, with sulfuric acid as the electroltye. Some of the early experiments with electrolytic drilling at the National Bureau of Standards, however, gave small-diameter holes 0.002 to 0.003 in. deep and having the general appearance of the secondary cone of a die. As a result of further extensive investigation, cones of 0.006 to 0.008 in. in depth, 0.0005 to 0.0015 in. in diameter, of smooth bore, and having the correct contour for secondary cones of dies, were produced at the bottom of mechanically drilled primary cones in from 40 to 80 minutes under controlled conditions, thereby eliminating the many hours of tedious drilling required to produce a similar cone mechanically. Furthermore, these electrically drilled cones in contrast to those produced mechanically give no evidence of added strain to the diamond when examined in polarized light.

\footnotetext{
${ }^{2}$ Paul Grodzinski, Diamond tools (The Vail-Ballou Press, Binghamton, N. Y., 1944).

3 A. Wehnelt, Elektrotech. Z, 20, 76 (1899).

4 W. Dawihl and O. Fritsch, Zat. Ver. Deut. Ing. 85, No. 11, 265 to 268 (March 15, 1941).
} 
A nonelectrolytic high-voltage method of drilling discovered by one of the authors was applied to pilot-drilling the primary cone, thereby further reducing production time of a die and effecting a saving in the amount of diamond powder required. This nonelectrolytic operation for pilot-drilling the primary cone will be designated "high-voltage method" to differentiate it from the "electrolytic method", by which the small secondary cone of a die is drilled.

\section{High-Voltage Drilling Method}

\section{Apparatus}

Cones 0.012 to $0.020 \mathrm{in}$. deep and having the contour shown in figure 2 can be drilled in diamonddie blanks in 10 minutes with the equipment shown in figure 3 . The application of high-voltage drilling to the production of diamond dies is given in a subsequent section that outlines the details of the Bureau method of making small dies. The equipment consists of the following parts: Adjustable-ratio transformer $V, 110 /(0-135) \mathrm{v}, 2$ amp. Transformer $T, 12,000 \mathrm{v}, 60$-cycle sign lighting, 150 va. Ammeter $A$, alternating-current, 2 -amp range. Capacitor $C, 0.004 \mu \mathrm{f}, 20,000 \mathrm{v}$. Quenched gap $G$, series of four to eight gaps. Electrode $E, 0.020$ in. in diameter-70 percent $\mathrm{Pt}, 30$ percent Ir wire. Brass block $B$, to support the diamond. Helical spring $S, 100$ turns of No. 22 enameled copper wire wound on a 9.5-mm mandrel, with platinum supporting hooks to insure electrical contact. This coil will apply

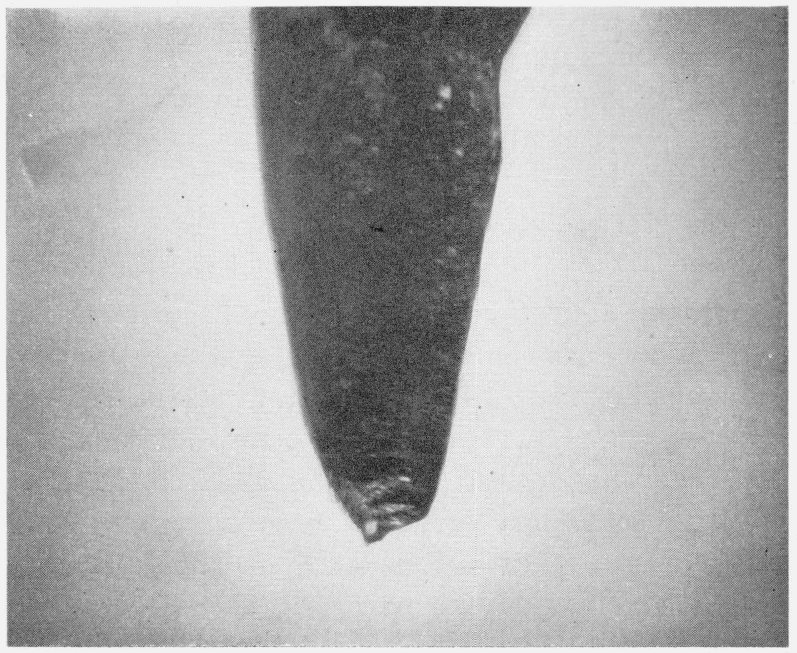

Figure 2.-Cone drilled with high voltage.

a $0.5 \mathrm{-g}$ load to the diamond when the electrode support is lowered $3 \mathrm{~mm}$ after contacting the diamond. Holder $H$, a 5-in. length of Pt-Ir tubing of 0.020 -in. inside diameter, 0.040-in. outside diameter, into which the electrode is slipped, and a cylindrical weight to extend the spring 20 to $30 \mathrm{~mm}$. A short length of Pt-Ir wire inserted into the upper end of the tube is bent to form a supporting hook. Elevating unit $L$, for raising and lowering the electrode. Rotating unit $R$, for rotating the electrode.

Figure 4 gives the wiring diagram. Leads from a 110-v 60-cycle alternating-current outlet are connected to the primary terminals of adjustableratio transformer $V$. The secondary of $V$ is

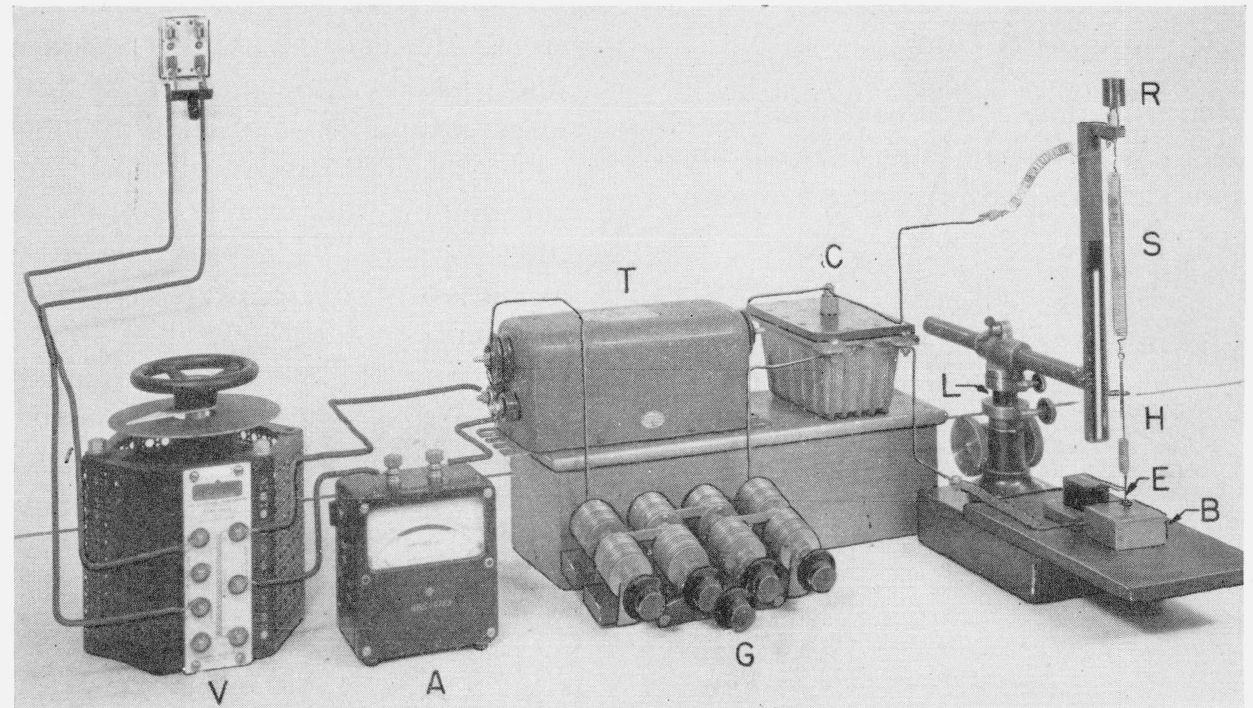

Figure 3.-High-voltage drilling apparatus. 


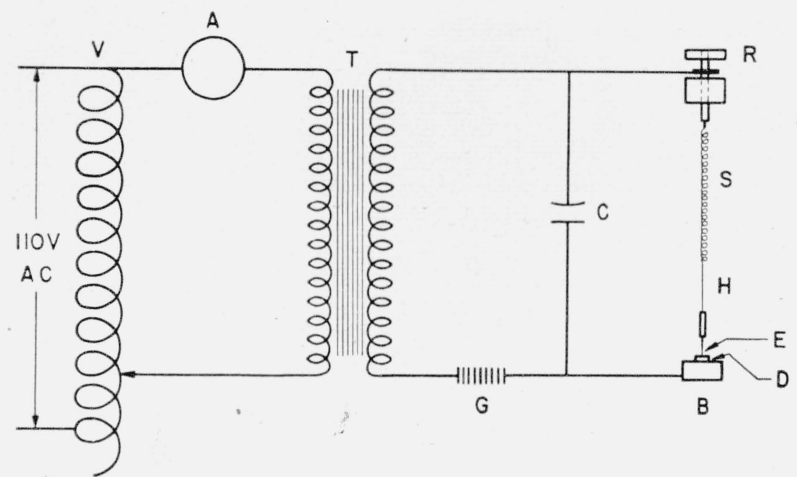

FIGURE 4.-High-voltage drilling circuit.

connected to transformer $T$. Ammeter $A$ is connected between $V$ and $T$ to read the primary current of transformer $T$. One secondary terminal of $T$ is connected electrically through the rotating device $R$, spring $S$, and holder $H$ to the drilling electrode $E$; the other terminal is connected through gaps $G$ to block $B$ supporting diamond $D$; capacitor $C$, without which little or no drilling takes place, is connected between $R$ and $B$. With the exception of $V$ and $A$, the apparatus should be enclosed in a metal shield to reduce radio interference.

\section{Drilling}

Procedure.-The electrode, previously ground to a 20- to 30-degree tapering point, is lowered to contact the diamond resting on $B$, and its support is then lowered an additional $3 \mathrm{~mm}$ to give a $0.5 \mathrm{~g}$ load on the diamond. Voltage is applied to the circuit in increasing magnitude by means of the adjustable-ratio transformer. Sparking first occurs across the quenched gaps and, with increased potential, a discharge takes place across the surface of the diamond between the electrode and the metal block. Without the quenched gaps in the circuit, this discharge is a more or less continuous arc that tends to produce a dark deposit on the diamond that interferes with the drilling action. Further increase in voltage produces a more intense white spark. Drilling then proceeds at an accelerated rate. Satisfactory drilling takes place with this equipment with current values of 0.8 to 1.4 amp in the primary circuit. The best value depends upon factors not fully under control of the operator. Although drilling is most rapid with the higher power values, values large enough to cause the diamond to develop a frosted surface should never be used.
Rate.-Drilling is more rapid for the greater current values, as indicated by the following data:

\begin{tabular}{|c|c|c|}
\hline Drilling time & Current & Cone depth \\
\cline { 1 - 2 } Min. & Amp. & In. \\
10 & 0.8 & 0.012 \\
10 & 1.2 & .016 \\
\hline
\end{tabular}

The rate of drilling and also the quality of the cones is affected somewhat by the load on the diamond and the initial shape of the electrode. More rapid and better drillings were obtained with the selected load of $0.5 \mathrm{~g}$ than with loads of 0.2 , $1.5,3$, or $8 \mathrm{~g}$. Drillings with electrodes having a 20- to 30-degree taper and a tip diameter of 0.002 to 0.003 in. give excellent results. Deeper and better-shaped cones are usually obtained by drilling for 10 -minute period and then redrilling with a resharpened electrode for another $10 \mathrm{~min}-$ utes than by drilling with the same electrode for 20 minutes. An occasional rotation of the electrode during the drilling operation tends to produce better-shaped cones.

Although the drilling rate diminishes with increased cone depth and becomes very low when the depth exceeds 0.025 in., if a previously drilled cone is broadened by mechanical coning, electrical drilling will again proceed at a rapid rate.

Precautions.-Whenever a drilling is to be made in a flat surface of a diamond, sidewise motion of the electrode must be constrained. This is accomplished by passing the electrode through a hole of slightly greater diameter in a supported arm above the diamond, as shown in figure 3 . Constraint is unnecessary when redrilling in a previously made cone. Movement of the diamond beneath the electrode is prevented by cementing it to its supporting surface with polystyrene lacquer or Duco cement.

The limiting condition for rapid drilling appears to be the power that can be applied before frosting of the diamond occurs. It has been found that frosting never results when the exposed electrode is operated below its reddening temperature, provided the diameter of the 70 percent $\mathrm{Pt}-30$ percent Ir electrode is not greater than $0.020 \mathrm{in}$. With an electrode 0.032 in. in diameter, frosting occurred without visible reddening. Consequently, electrodes $0.020 \mathrm{in}$. in diameter should be used, and the current should be adjusted to 
prevent visible reddening of the electrode immediately above the diamond. Although this is not a particularly fortunate criterion, its employment does permit rapid drilling without frosting of the diamond. It is evident, therefore, that high-voltage drilling at the present time is a process that requires continuous supervision by the operator. The spark should be viewed through protective glasses to avoid injury to the operator's eyes.

One other condition should be considered. As the drilling nears the bottom of the diamond, the current tends to be conducted through the diamond, the discharge around the diamond ceases, and the diamond tends to overheat. This condition may be overcome by mounting the diamond to be drilled upon another flat-surfaced diamond, silver-soldered in a cavity in brass block $B$, figure 3 , and protruding about $0.5 \mathrm{~mm}$ above the metal surface, thereby insulating the die blank from the brass block.

\section{Electrolytic Method for Drilling Secondary Cones}

\section{Apparatus}

The electrolytic method for drilling the secondary cones of small dies is a straightforward procedure requiring but a small amount of inexpensive equipment. It consists of the following parts: Variable-ratio transformer $V, 110 /(0-135)$ v, 2 amp. Ammeter $A$, alternating current, 0 - to 1 - or 0 - to 2 -amp range. Capacitor (optional) $10 \mu \mathrm{f}, 600 \mathrm{v}$. Electrodes $E_{1}$ and $E_{2}$, hard-drawn 70 percent Pt30 percent $\mathrm{Ir}$ wire, $0.020 \mathrm{in}$. in diameter. Elevating unit $L$, for raising and lowering $E_{1}$. Rotating unit $R$, for rotating $E_{1}$. Helical spring $S, 75$ turns of No. 30 enameled copper wire wound under slight tension on a 7-mm mandrel. Platinum suspension hooks are soldered to the ends of the coil to insure electrical contact. This coil will apply a load of about $0.1 \mathrm{~g}$ to the diamond when the electrode support is lowered $1 \mathrm{~mm}$ after the electrode contacts the diamond, and about $0.2 \mathrm{~g}$ when it is lowered $3 \mathrm{~mm}$. The load may be increased by using larger wire or by decreasing either the diameter or the number of turns of the coil. Holder $H$, a 5 -in. length of Pt-Ir tubing of $0.020 \mathrm{in}$. inside diameter, $0.040 \mathrm{in}$. outside diameter, into which $E_{1}$ is slipped, and a cylindrical weight to extend the spring $S, 20$ to $30 \mathrm{~mm}$. A short length of $\mathrm{Pt}$ or $\mathrm{Pt}-\mathrm{Ir}$ wire inserted in the

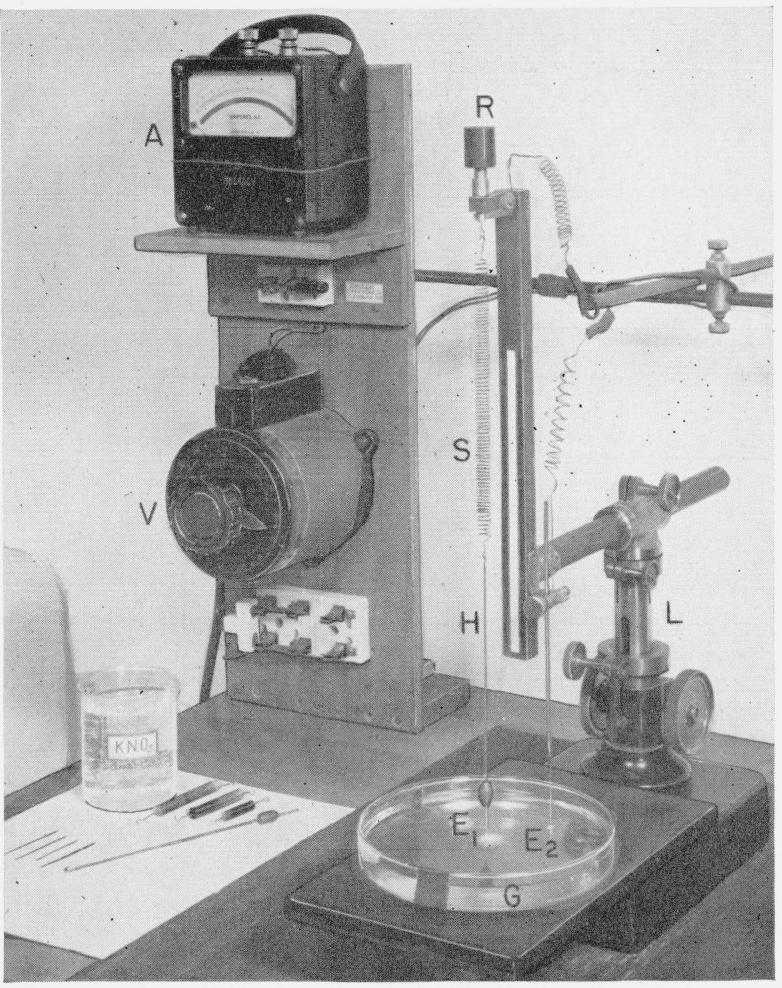

FIGURE 5.-Electrolytic drilling apparatus.

upper end of the tube is bent to form a supporting hook. Electrode $E_{2}$ should be so mounted as to permit vertical adjustment. Glass container $G$, petri dishes 6 in. $(150 \mathrm{~mm})$ in diameter by 1 in. $(25 \mathrm{~mm})$ deep are satisfactory. A small glass pillar about $8 \mathrm{~mm}$ high is cemented in the bottom of the container to support the diamond. The assembled equipment is shown in figure 5. The wiring diagram is shown in figure 6 .

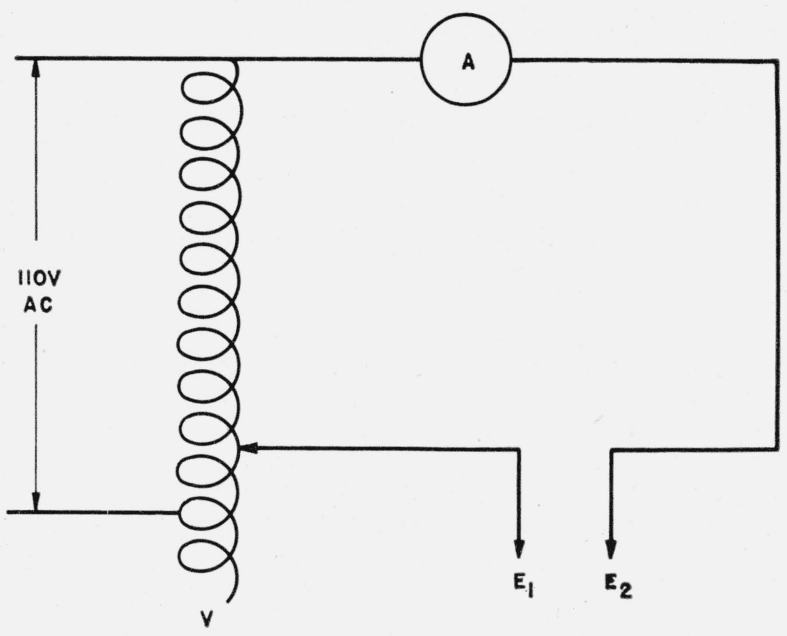

Figure 6.-Electrolytic drilling circuit. 


\section{Drilling Procedure}

Electrode $E_{1}$ is centered in the previously formed primary cone of the die blank, which is cemented with polystyrene lacquer or Duco cement on the small glass pillar in the container. After the electrode touches the bottom of the cone, its support is lowered $3 \mathrm{~mm}$ to apply a predetermined load on the diamond. Electrode $E_{2}$ should dip 4 to $5 \mathrm{~mm}$ deeper than $E_{1}$. Electrolyte is then poured into the container until the diamond is immersed to a depth to give 0.5 to $0.7 \mathrm{amp}$ when the correct drilling potential is applied.

By using a 10 percent, by weight, aqueous solution of $\mathrm{KNO}_{3}$ as the electrolyte and applying $85 \mathrm{v}$ across the electrodes, a small conical hole will be produced in the diamond. The shape of the cone is improved by occasionally rotating the drilling electrode. This rotation is accomplished by turning $R$ through about 90 degrees. If, at the start, the drilling electrode $E_{1}$ had a 10-degree taper and a tip diameter of $0.001 \mathrm{in}$. the cone produced in 40 minutes will be 0.006 in. deep and have approximate top and bottom diameters of 0.002 and 0.0004 in., respectively. The tapered electrode will have shortened about $2 \mathrm{~mm}$ during the drilling operation, and its tip ( $A$, fig. $7, A$ ) will have the

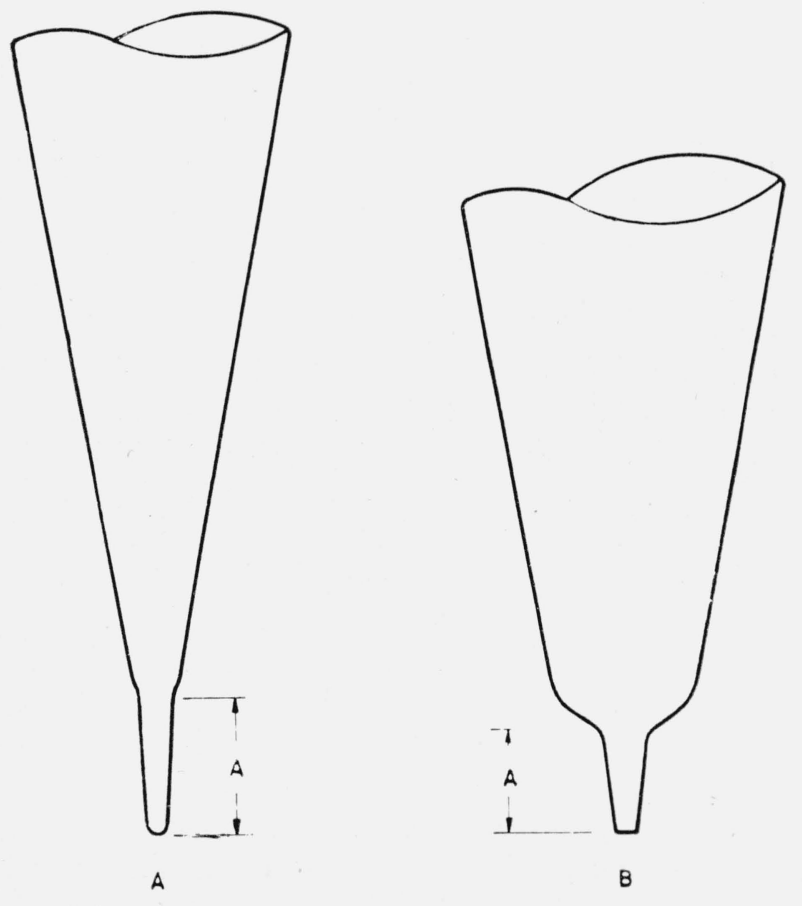

Figure 7.-Drilling electrodes. $A$, With narrow shoulder; $B$, with broad shoulder. shape of the hole and be of somewhat smaller dimensions. If a more blunt electrode is used, the resulting cone will have the same general shape as in the first case, but will be less deep; the shortening of the electrode will be less, and its final profile will show a broad shoulder above its tip ( $A$, fig. $7, \mathrm{~B})$. This seems to indicate that drilling is retarded by the time required for the electrolytic etching of the electrode.

\section{Factors That Affect Drilling}

Variables that affect the drilling are well within control of the operator, thereby permitting surprisingly close duplication of results. A discussion of several factors that affect the drilling follows.

Electrodes: Composition.-Both electrodes should be of a noble metal or an alloy of noble metals to withstand the electrolytic action. The composition of the deep-dipping electrode is less critical than that of the drilling electrode. The most satisfactory material tried thus far for the latter is hard drawn 70 percent $\mathrm{Pt}-30$ percent $\mathrm{Ir}$ wire. Hard-drawn Pt wire drills fully as rapidly as this alloy but gives cones of somewhat greater diameter.

Diameter.-Electrodes 0.020 in. in diameter are sufficiently rigid to retain their shape during the pointing operation and are more economical to use than those of greater diameter.

Shape.-The drilling electrode is ground with an 8- to 10-degree taper to form a tip 0.001 to 0.002 in. in diameter. The rate of drilling is retarded if the tip diameter is large. The bottoms of the cones . tend to be somewhat irregular when tips less than $0.001 \mathrm{in}$. in diameter are used.

No attention need be given to the shape of the nondrilling electrode.

Electrolyte: Composition.-From tests of aqueous solutions of 40 electrolytes, including salts, bases, acids, and several combinations of salts, potassium nitrate $\left(\mathrm{KNO}_{3}\right)$ was selected as the most desirable for drilling the secondary cone of the die. Although drilling is possible with many of the other electrolytes, these were discarded for various reasons, including slowness of drilling, inability to drill deep cones, roughness or irregularity of the cones, release of irritating fumes, critical requirements for duplication of drillings, and contour of the resulting cone. The majority 


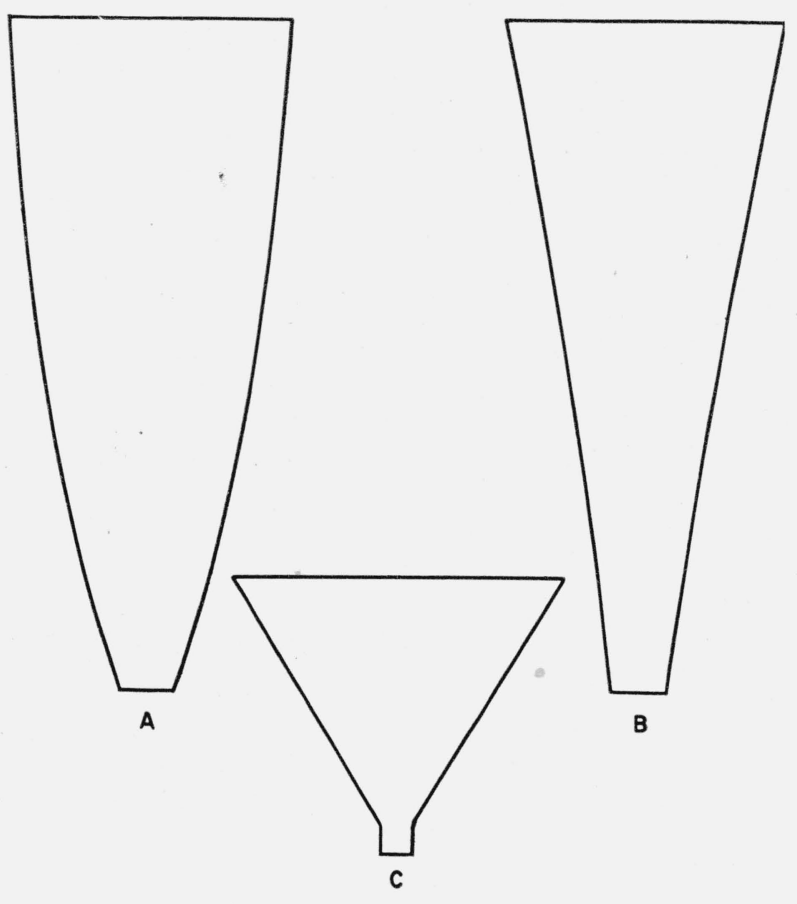

Figure 8.-Cone profiles with various electrolytes.

$A$, With several different electrolytes; $B$, with $\mathrm{KNO}_{3} ; C$, with NaCl.

of electrolytes give cones of contour $A$, (fig. 8) in contrast to the more desirable shape $B$, (fig. 8) for die secondary cones produced with $\mathrm{KNO}_{3}$. One electrolyte, $\mathrm{NaCl}$, gives a funnel-shaped cone $C$, (fig. 8) that has a useful application, to be discussed later, in making electrically drilled dies. Slight impurities in the electrolyte do not affect the drillings appreciably, but it is well to use distilled water. The addition of a small quantity (say, $0.2 \%$ ) of aerosol to the solution reduces the spray from the liquid without interfering with the drilling.

Concentration.-Excellent drillings may be made with 3 to 10 percent $\mathrm{KNO}_{3}$ concentrations and with 3 to 6 percent $\mathrm{NaCl}$ concentrations when the proper corresponding voltages and currents are used. Lower concentrations are less desirable from the standpoint of quality of the cones produced, whereas concentrations above the upper limits do not appear superior.

Applied Load.- In general, the magnitude of the load applied by the electrode to the diamond affects the diameter and depth of the cone. A load of 0.1 to $0.2 \mathrm{~g}$ is used to drill dies less than $0.001 \mathrm{in}$. in diameter. Dies of somewhat larger diameter are produced by increasing the weight. Drilling is not as rapid with the larger loads, however, and to drill a cone of the required depth with a $2-\mathrm{g}$ load may necessitate resharpening the electrode and redrilling for an additional 40minute period. The contour of the lower part of the cone tends to be irregular when loads of less than $0.1 \mathrm{~g}$ are used.

Drilling Period.-The rate of drilling obeys the law of diminishing returns. Cones 0.006 in. deep are produced in the first 40 to 45 minutes, after which the drilling proceeds rather slowly. With longer periods the bottoms of the cones tend to become slightly irregular in shape. The best procedure when deeper cones are required is to remove and resharpen the electrode after a 40minute drilling. A second 40-minute drilling will then increase the cone depth to 0.0075 to $0.008 \mathrm{in}$. Cones of greater depth will require additional drillings.

Effect of Capacitance.-The effects upon drilling resulting from changes in the electrical characteristics of the circuit have been studied. Except for those effects produced by adding capacitance to the circuit, the results will not be reported at this time.

In parallel.-Two beneficial effects are noted when a capacitor of 5 - to $10-\mu \mathrm{f}$ capacitance is placed in parallel with the electrodes: (a) the shape of the bottom of the cone is improved, and (b) decomposition of the electrolyte is reduced, so that little, if any, attention is needed to maintain the solution at its proper level. One disadvantage noted in drilling very small dies with parallel capacitance is that a second drilling usually increases the diameter 0.0001 to 0.0003 in.

In series.-The drilling rate is greatly accelerated by placing $20-\mu$ feries capacitance in the circuit and increasing the potential to 220 to 230 $\mathrm{v}$; cones 0.006 to 0.008 in. deep and 0.0012 to 0.0015 in. in diameter can be drilled in 15 to 20 minutes. The tendency of these cones to be irregular in shape and to wander from the die axis makes the use of this circuit inadvisable until better control of the cones can be attained.

Voltage-Current: Relationship for different electrolytes.-Figure 9 shows the voltage-current curves for three electrolytes of indicated concentrations for maximum current values of $0.8 \mathrm{amp}$ and an applied load of $0.12 \mathrm{~g}$. As the voltage increases from zero, a value $A$ is reached for each electrolyte at which visible sparking begins. Sparking becomes more vigorous with increasing 
voltage, until at voltage $B$ the current suddenly becomes much lower. This transformation, unmistakable with $\mathrm{NH}_{4} \mathrm{Cl}$ and $\mathrm{H}_{2} \mathrm{SO}_{4}$, is less obvious with $\mathrm{KNO}_{3}$, although it may be readily determined by means of an oscilloscope. With $\mathrm{NH}_{4} \mathrm{Cl}$ and $\mathrm{H}_{2} \mathrm{SO}_{4}$, the vigorous sparking subsides with the drop in the current and resumes when the current begins to increase again at $C$. The decrease in sparking is less evident with $\mathrm{KNO}_{3}$, possibly because the current increases immediately after the transformation at $B$. These characteristics are common to many electrolytes.

Drilling of the diamond appears to begin at $A$ and increases in rate until $B$ is reached. Between $B$ and $C$, the drilling electrode becomes highly polished, and little, if any, drilling takes place. Beyond $C$ the electrode becomes pitted and rapidly deteriorates.

Drilling current.-For a given voltage, the current increases with the depth of immersion of the drilling electrode and the concentration of the electrolyte. With concentrations ordinarily used, shallow immersions giving currents less than 0.3 amp at transition $B$ are unsatisfactory because the drilling action becomes irregular. Also, deep immersions giving currents greater than 1 amp are unsatisfactory because the drilling electrode becomes pitted. Immersions giving currents of 0.5 to $0.7 \mathrm{amp}$ have proved the most satisfactory.

Drilling voltage. Drilling is most rapid for voltage values in the region of $B$ immediately before transformation occurs. The voltage for best drilling increases as the concentration of the electrolyte is reduced and increases to a lesser degree with decrease in the applied load and with increase in the depth of immersion of the electrode. With electrolyte $\mathrm{KNO}_{3}, 0.2$-g applied load, and 0.5 - to 0.7 -amp current, excellent cones are produced by using 85 to $90 \mathrm{v}$ for 10 -percent concentrations; 95 to $100 \mathrm{v}$ for 5 -percent concentrations, and $110 \mathrm{v}$ for 4-percent concentrations. Excellent funnel-shaped holes are produced with electolyte $\mathrm{NaCl}$ by using 90 to $95 \mathrm{v}$ and $110 \mathrm{v}$ respectively, with 5-percent and 4-percent solutions. By selecting the proper concentration for a given electrolyte, maximum drilling will take place at line voltage, thereby eliminating the need for a variable-ratio transformer. Such a transformer, however, permits greater flexibility in drilling conditions.

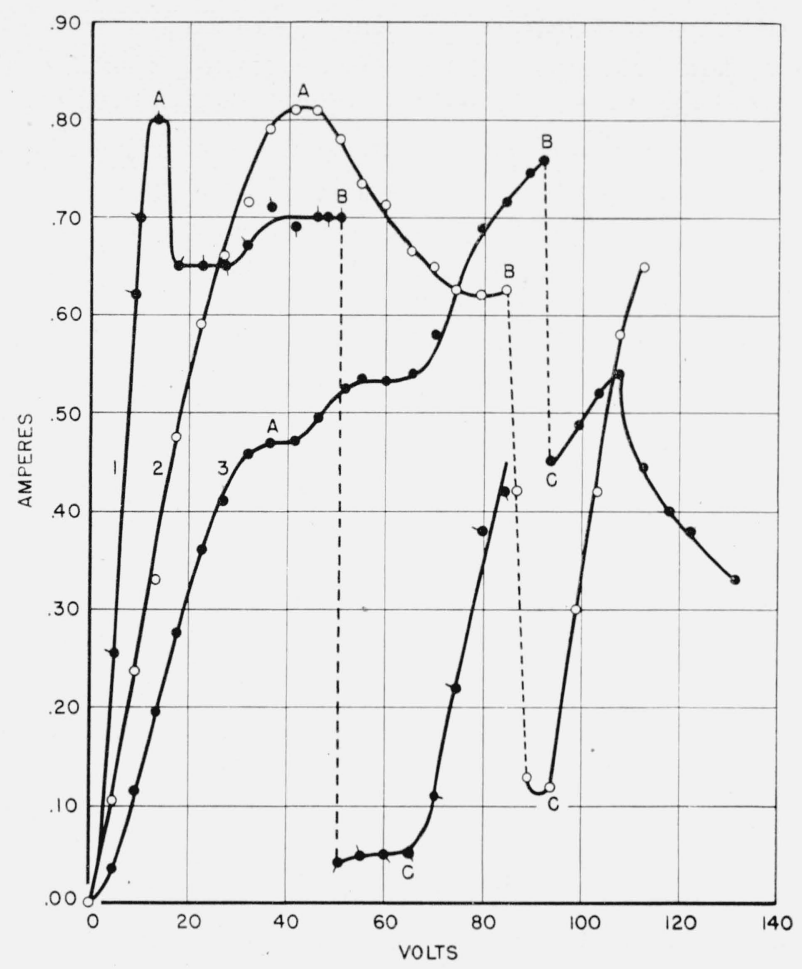

Figure 9.-Voltage-current curves for $\mathrm{H}_{2} \mathrm{SO}_{4}, \mathrm{NH}_{4} \mathrm{Cl}$, and $\mathrm{KNO}_{3}$

Curve 1, $25 \% \mathrm{H}_{2} \mathrm{SO}_{4}+75 \% \mathrm{H}_{2} \mathrm{O}$ (by weight); $2,8 \% \mathrm{NH}_{4} \mathrm{Cl}+92 \% \mathrm{H}_{2} \mathrm{O}$ (by weight); $3,10 \% \mathrm{KNO}_{3}+90 \% \mathrm{H}_{2} \mathrm{O}$ (by weight).

\section{Coning and Polishing Machine}

As stated in section IV, electrical methods are used to pilot-drill the primary cone and to drill the secondary cone when making small dies at the Bureau. Mechanical operations are used to complete the primary cone and to polish the dies. These mechanical operations are performed much more effectively with a machine developed at the Bureau than with customary drilling and polishing machines.

Previous coning, or drilling, machines were designed to drill without the aid of pilot holes by tapping the diamond against a rapidly rotating steel needle, with diamond powder as the abrasive. This is essentially a combined grinding and stardrilling process in which grinding or drilling is caused by the action of the abrasive between the needle and the diamond. Deepening of the hole depends upon the breaking away of minute cleavage fragments by particles of diamond powder beneath the needle. Regardless of the speed of rotation, the axis of the drill is essentially stationary. Therefore, any forward progress of the 
drill must be caused by the hammering action of its tip. Since the hardness of diamond is about 10 times that of a steel needle, it is obvious that the fine-pointed needle will be blunted after a few taps when drilling small dies. Most of the time required to drill a die of say 0.0006-in. diameter will consequently be spent in sharpening the drill. From the foregoing discussion it is apparent why 75 to 150 hours may be required to drill a secondary cone 0.006-in. in length. When drilling dies 0.003 to $0.080 \mathrm{in}$. in diameter, the size of the drill tip is sufficient to withstand considerable shock. Appreciable striking force and coarse-grained powder can be used for these larger dies, resulting in rather rapid drilling. This treatment, however, produces strains and fractures in the cone surface.

Regrinding of the drill when making small dies is greatly reduced by the introduction of pilotdrilling as the tip of the drill in this case does not touch the diamond. The conical surface of the drill, which is charged with abrasive and has considerable surface speed, cuts the cone to the required form - the action becoming less of a hammering and more of a grinding and cutting process. The multiple-head vertical-spindle machine, figure 10, for coning and polishing was designed to enhance this action by reducing the hammering action, giving a better flow of abrasive around the drill and affording a longer time of contact of the drill and diamond.

Each spindle of the machine (shown in fig. 11) runs in two cylindrical phosphor-bronze bushings, $B$, which are pressed into recesses in the crossbars and can be easily replaced when worn. The steel drilling needle, $N$, centered in a hole drilled in the axis of the spindle, $S$, is ground to the desired taper with a small hand grinder fitted with an Alundum wheel.

The oscillating rod, $R$, that supports the die also slides in two cylindrical bronze bushings. A $U$-shaped bronze spring, $U$, is attached to the lower end of each rod, and a cylindrical cap, $C$, having a hole of about 1-mm diameter drilled in its center fits onto the top of the rod.

Bar $D$, having an adjusting screw, $A$, in the outer end is attached at $F$ to the rear crossbar by a flexure plate. This bar is moved up and down by the cam action of a shaft, $E$, having the end bearings turned eccentric to its axis. The speed of the shaft is governed by a 10-to-1 or 100-to-1 reduction gear box inserted between the counter and cam shafts.

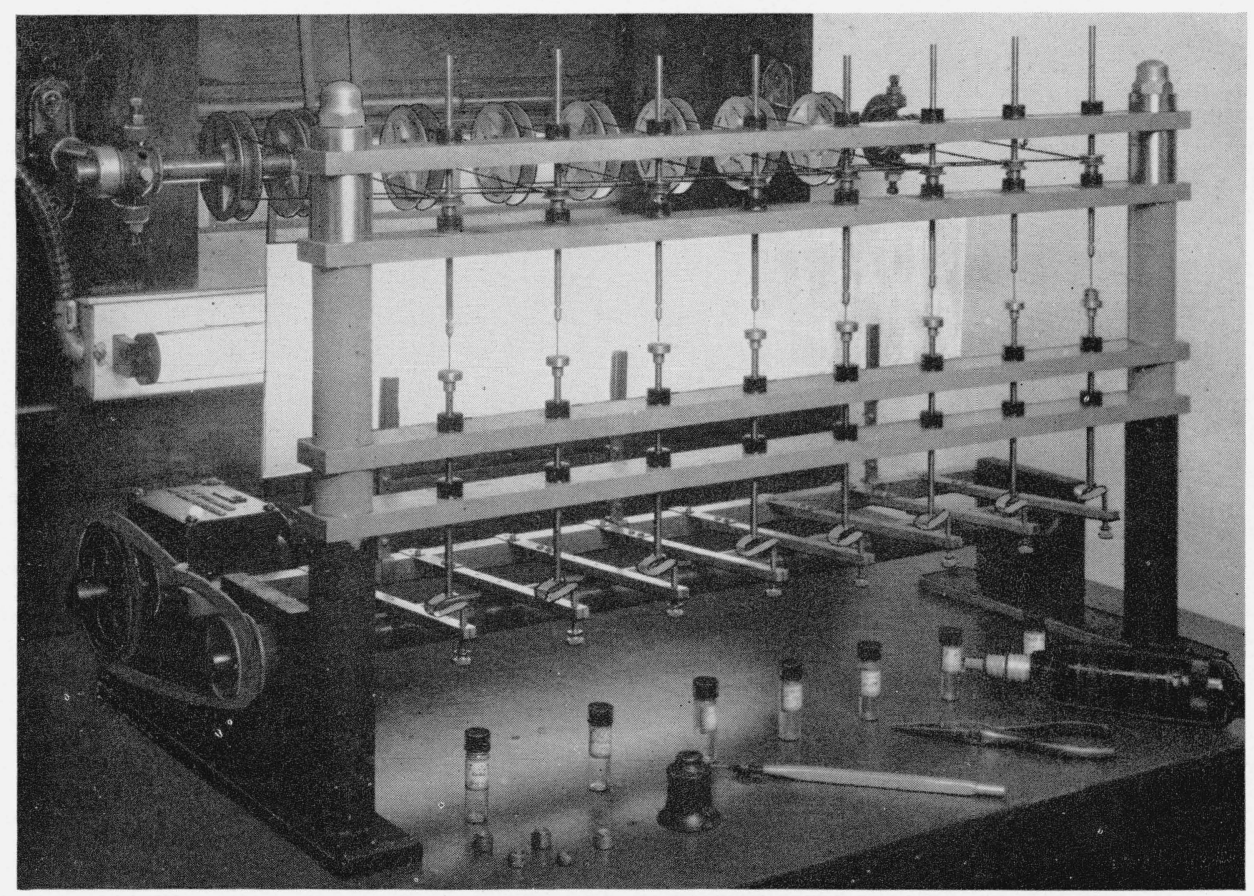

Figure 10.-Machine for coning and polishing. 


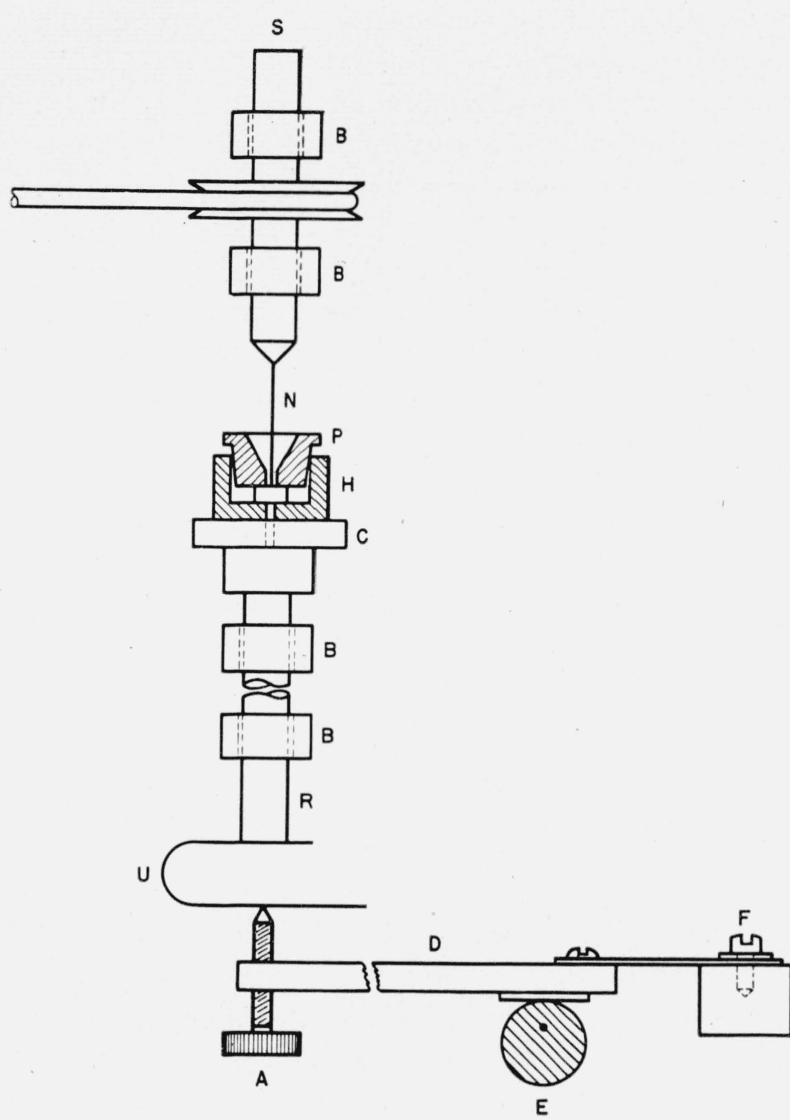

FIGURE 11.--Individual spindle of coning and polishing machines

The pressure exerted by the diamond on the needle and the time of contact of the two is regulated by adjusting the screw, $A$, and sliding it from the tip to the base of the bottom leaf of spring, $U$, by a rotation of the cam follower, $D$, about its point of attachment, $F$, to the rear crossbar.

For shaping or countersinking the primary cone, the die is held in a cylindrical cup, $H$, of about $1 / 2$-in. external and $3 / 8$-in. internal diameter. A plug, $P$, that fits the cup has a conical cavity drilled through from the top, which acts as a reservoir for the abrasive liquid. The top of the die is waxed to the bottom of the plug, which is then pressed firmly into the cup. The assembly is then placed on the cap, $C$, of the oscillator rod, where it slides sideways until the axis of the primary cone alines itself with axis of the drill. It is there coned until the tip of the drill reaches the bottom of the pilot drilling. The plug is easily removed with a pair of pliers, and the unmounted die can be examined for defects under good illumination with a microscope having a magnification of about 100 diameters.

\section{NBS Method of Making Small Dies}

The results obtained by the two electrical drilling methods may be summarized as follows: (1) High-voltage drilling-rough cones 0.012 to 0.020 in. deep and 0.003 to 0.004 in. in diameter can be drilled in 10 minutes. (2) Electrolytic drilling - smooth cones of correct size and contour for the secondary cones of small dies can be drilled in 40 to 80 minutes.

Considerable variation exists in the equipment and requirements of different die manufacturers. Consequently, each producer must determine how and to what extent he can apply these electrical methods most advantageously. The following step-by-step procedure is employed at the National Bureau of Standards to produce small dies.

\section{Selection, Preparation, and Inspection of Die Blanks}

Dies having a diameter of 0.002 in. or less require a thickness of 0.044 to 0.064 in. Diamonds of one-sixth to one-fourth carat suffice for this purpose.

The plane-parallel surfaces and the viewing window are cut on a rotating cast-iron lap, with diamond powder as the abrasive. The cutting action is accelerated at the Bureau by the application of an electric arc. ${ }^{5}$

After the three facets are cut, the diamonds are examined under the microscope. Those showing flaws, carbon spots, or other other imperfections in the central portion of the stone that might weaken the die or interfere with the drilling are rejected.

\section{Drilling the Die}

The sequence of operations used at the Bureau to produce small dies is given in figure 12, operations 1 to 10 .

Drilling the Primary Cone.-The primary cone is produced by a combination of high-voltage pilot drilling and mechanical coning, as indicated in figure 12 , operations (1) to (6).

Operation 1. Spotting.-The blank is first cemented for high-voltage drilling on the pillar of brass block $B$, figure 3 . The 0.020 in. 70 per-

${ }^{5}$ Chauncey G. Peters, Karl F. Nefflen, and Forest K. Harris, Diamond cutting accelerated by an electric arc, J. Research NBS 34. 587 (1945) RP1657. 

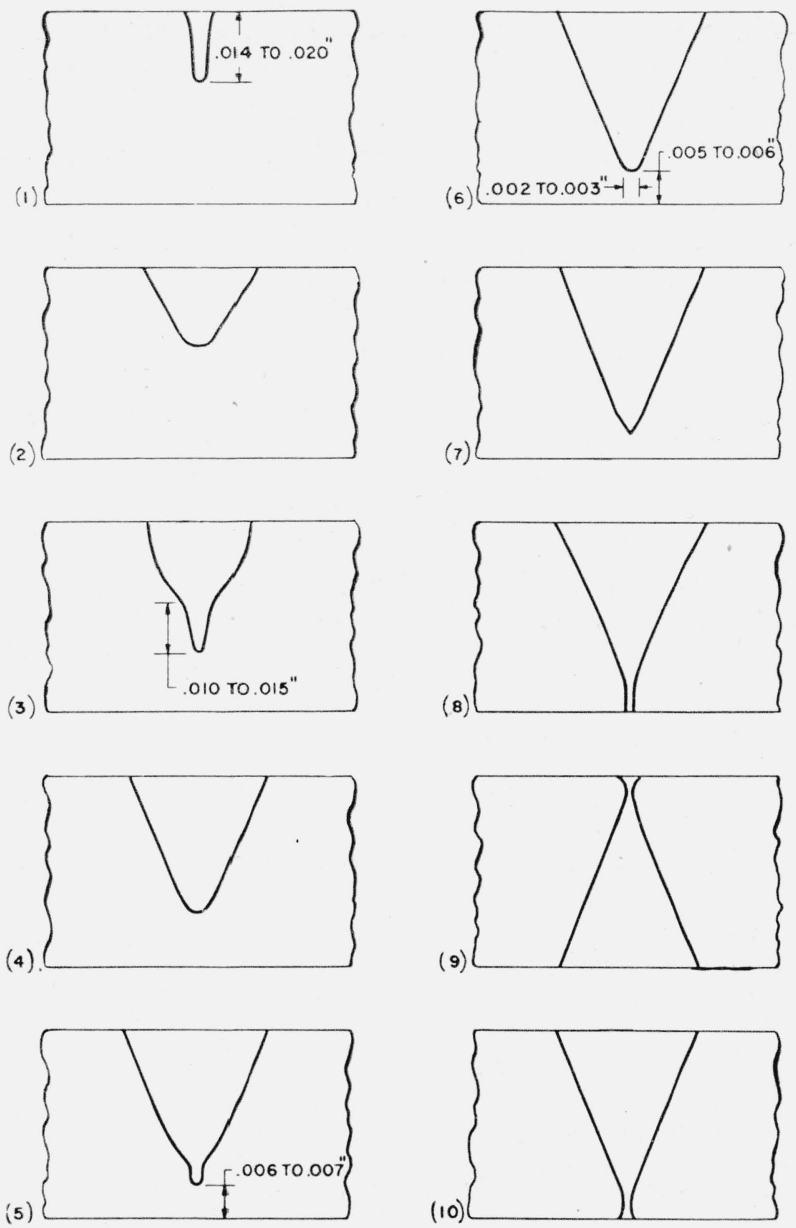

Figure 12.-Sequence of drilling operations.

Operations 1 to 6 , drilling the primary cone; operations 7 and 8 , drilling the secondary cone; operation 9 , relieving the back opening; operation 10 , polishing

cent Pt-30 percent Ir. electrode is ground with a 20-degree taper to form a 0.002 to $0.003 \mathrm{in.} \mathrm{tip,}$ and is constrained from sidewise motion by passing it through the hole in the supporting arm, and is centered on the upper surface of the blank. The elevating unit is next lowered $3 \mathrm{~mm}$ to give the required electrode pressure. Voltage is then applied to give an ammeter reading of 0.8 to 1.4 amp. ${ }^{6} \quad$ By continuing the drilling for 10 minutes a cone 0.014 to $0.020 \mathrm{in}$. deep, figure 12 (1) and figure 2 , is produced that serves as a pilot hole for the next operation.

6 These values represent the primary current in the high-voltage transformer, and will of course vary as different transformers are used. The operator will observe the intense blue-white spark between electrodes and across the face of the diamond, and may adjust the power by varying the input voltage until the needle electrode begins to show incandescence. The input voltage is then reduced to the point at which the electrode shows no redness, and the primary current is noted. Thereafter, the primary current in the transformer is a useful criterion of proper spark conditions.
Operation 2. First mechanical coning.-The cone is next countersunk to the shape in figure 12 (2), by means of the coning machine shown in figure 10 . The spindle speed is about 5,000 rpm for this operation, and the diamond makes about 300 oscillations per minute. The drill is a steel needle 0.03 to $0.04 \mathrm{in}$. in diameter ground to a 45 -degree point. Grade $40{ }^{7}$ diamond powder in gelatin solution ${ }^{8}$ is used as the abrasive. This coning operation usually requires 30 to 40 minutes; the actual manhours required are few, however, because one person can operate 10 or more spindles.

Operation 3. Fore-drilling.-This is a repetition of the high-voltage drilling in operation 1, except that in this case no constraint of the electrode is required. Occasional rotation of the electrode during the drilling tends to improve the shape of the cone. The cone produced in 10 minutes is 0.010 to $0.015 \mathrm{in}$. deep. Serving as a pilot drilling for the mechanical coning operation, it reduces appreciably the time required to drill the primary cone.

Operation 4. Second mechanical coning.-This is a repetition of operation 2 .

Operation 5. Final fore-drilling.-The diamond is again drilled as in operation 3. For this drilling the operator must exercise judgment as to the drilling time required to obtain the correct end point. The bottom of the drilled cone should be 0.006 to $0.008 \mathrm{in}$. from the back surface of the diamond. For exceptionally thick blanks, additional drillings and conings may be required.

Operation 6. Final coning.-Greater care is taken in this operation than in operations 2 and 4 . The final primary cone, figure $12(6)$, should be of symmetrical shape, free from drilling rings, and have either a polished or fine-matt surface. The diameter of the cone immediately above its apex should be between 0.002 and 0.003 in. to assure good blending of primary and secondary cones. Grade 20 diamond powder is used for the final coning operation.

Drilling the Secondary Cone: Operation 7. Electrolytic drilling with $\mathrm{NaCl}$ - - As noted in section VI, electrolyte $\mathrm{NaCl}$ gives a wide angle, funnel-shaped cone, whereas electrolyte $\mathrm{KNO}_{3}$ produces a relatively long, narrow cone of correct

7 See, NBS Commercial Standard CS 132-45, Grading of diamond powder (1945).

${ }^{8}$ Distilled water, 1 liter; gelatin, $1 \mathrm{~g}$; sodium carbonate, $0.1 \mathrm{~g}$ (approximately) to give a $\mathrm{pH}$ of $9 . \mathrm{Ph}$ (n)ol crystals are added to prevent bacterial growth. 
size and shape for the secondary cone of a small die. There is a tendency, however, for the secondary cone to be slightly to one side of the primary cone axis when a drilling with $\mathrm{KNO}_{3}$ is made directly in a primary cone that has a broad, unpointed or irregular bottom. Excellent alinement and better blending of the primary and secondary cones are obtained by making a first drilling with $\mathrm{NaCl}$ as an electrolyte and a final drilling with $\mathrm{KNO}_{3}$. In view of these advantages, the additional 30 minutes required for an $\mathrm{NaCl}$ drilling appears well spent. The following drilling procedure is used (see fig. 5 and section VI).

The 0.020 in. diameter 70 percent $\mathrm{Pt}-30$ percent Ir drilling electrode is ground with an 8- to 10 degree taper to a 0.002 to $0.003 \mathrm{in}$. diameter tip. The diamond, previously cemented on the post in the container, is placed beneath and in the axis of the electrode. The electrode support is lowered an additional $3 \mathrm{~mm}$ after the electrode contacts the bottom of the primary cone to give about $0.2 \mathrm{~g}$ pressure on the diamond. The nondrilling electrode should dip about 4 to $5 \mathrm{~mm}$ deeper in the container than the drilling electrode. A 5percent aqueous solution of $\mathrm{NaCl}$ is then poured into the container, immersing the diamond sufficiently (approximately $2 \mathrm{~mm}$ ) to give a current of about $0.7 \mathrm{amp}$ when $90 \mathrm{v}$ are applied to the circuit. Drilling with $90-v$ potential is continued for 30 minutes. This gives a sharp apex to the cone, as shown in figure $12(7)$.

Operation 8. Electrolytic drilling with $\mathrm{KNO}_{3}$.The procedure for drilling the secondary cone of the die is similar to that given for operation 7 . However, for this drilling the electrolyte is a 10percent aqueous solution of $\mathrm{KNO}_{3}$, and the tip diameter of the drilling electrode is somewhat smaller, 0.0010 to 0.0015 in., for more rapid drilling. Current and voltage values are $0.7 \mathrm{amp}$ and $90 \mathrm{v}$, respectively. Greater voltages will be required for rapid drilling if lower electrolytic concentrations are used. At the end of a 40- to 45-minute drilling period, the drill will have pierced the back face of the die, giving a smoothbore cone having a length of about $0.006 \mathrm{in}$. and a diameter at the bottom of 0.0005 to $0.0006 \mathrm{in}$. Its general appearance is shown in figure 12 (8) and in figure 13.

If the initial distance between the bottom of the final primary cone and the back of the die

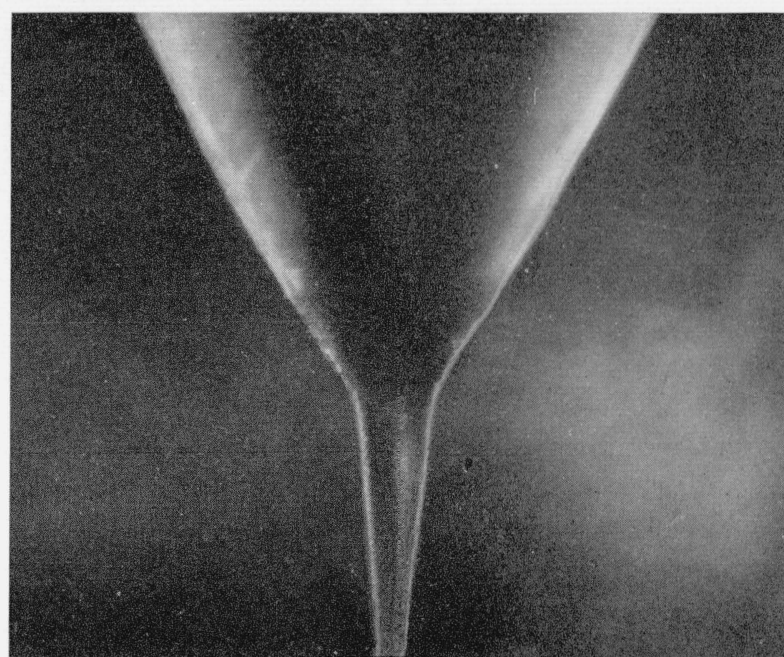

Figure 13.-Die after piercing. $\times 150$.

was greater than 0.005 in., the drilling may not have pierced the back surface and an additional drilling with a resharpened electrode and a fresh solution of $\mathrm{KNO}_{3}$ will be required.

Relieving the Back Opening: Operation 9. Giving the die back-relief.-The sharp edge formed at the intersection of the secondary cone and the back surface is given a slight countersink to prevent damage by chipping when wire is drawn through the die. This is accomplished by inverting the die beneath the drilling electrode and drilling electrolytically from the back, using a 5 -percent $\mathrm{NaCl}$ electrolyte. The electrode is ground with a 30-degree taper to a fine tip for insertion in the bottom of the secondary cone. Sufficient back-relief is obtained with a 4 - or 5 -minute drilling at $70 \mathrm{v}$ and 0.5 to $0.7 \mathrm{amp}$, as shown in figure 12 (9 and 10). The appearance of the relief is somewhat improved by placing a 10- $\mu \mathrm{f}$ capacitance in parallel with the electrodes.

Polishing: Operation 10. Finishing the die mechanically. - This operation is designed to improve the roundness of the die and to shape and polish its working parts.

The die is placed directly on the cap of the oscillator rod of the polishing machine, figure 11, which operates with a spindle speed of 7,000 rpm and oscillates the die 30 times per minute. A No. 7 to No. 10 steel sewing needle is ground to a long taper and, as it wears, is allowed to feed through the die into the hole drilled in the cap. The abrasive for polishing is diamond powder in pine 
oil; grade 6 powder is used for fast cutting and grade 4 powder to produce the final polish.

The polishing operation is continued until the cone is circular, well-polished, and has a bearing of 0.001-in. length and 4-degree taper. The diameter of dies produced under the conditions described in operations 1 to 10 will usually be in the range of 0.0006 to 0.0008 in. Figure 14 shows two finished dies of 0.0008-in. diameter. Dies having short secondary cones have been drilled with diameters as small as $0.0003 \mathrm{in}$. Dies of 0.0010 to 0.0012 -in. diameter are produced by increasing the load on the electrode or by using pure $\mathrm{Pt}$ electrodes when drilling the secondary cone. It has also been found that repeated drillings with $10-\mu \mathrm{f}$ capacitance in parallel with the electrodes give larger diameter cones. For
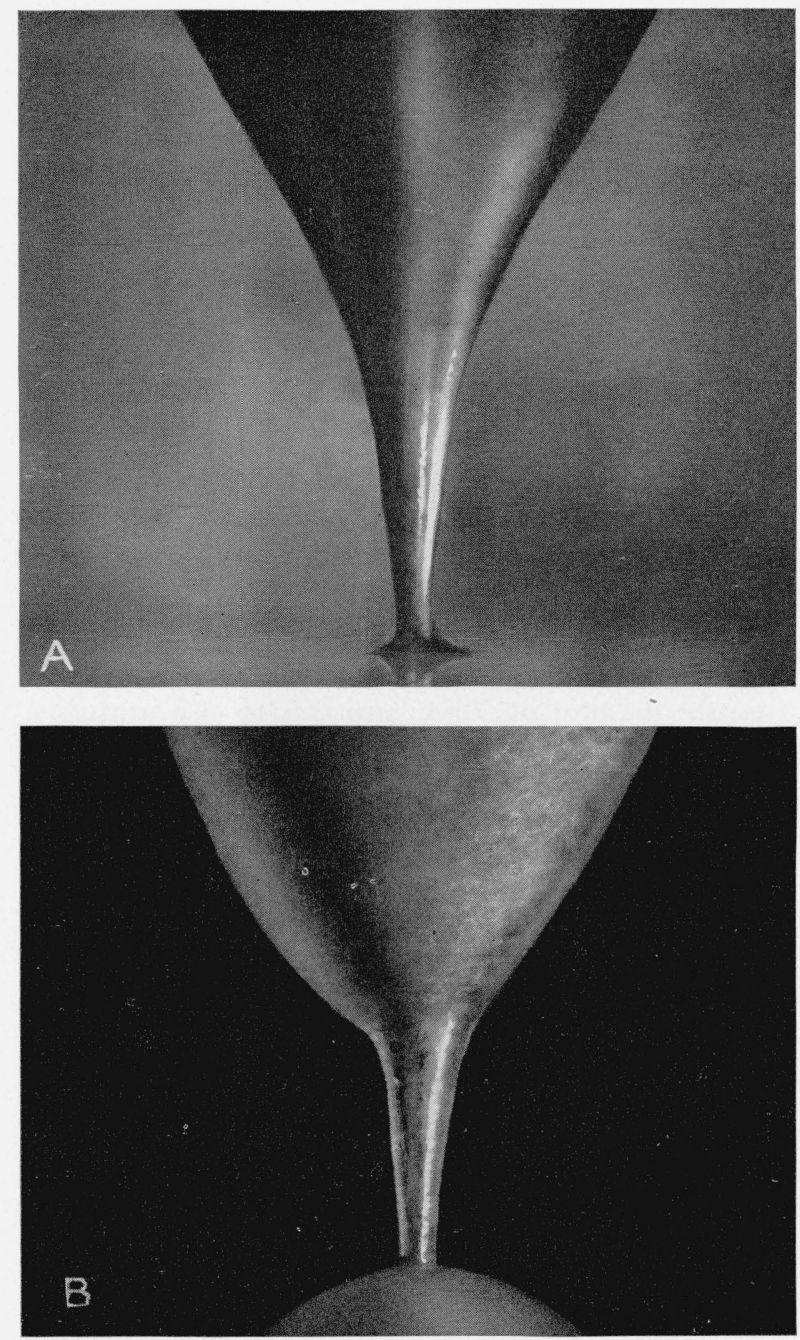

Figure 14.-Finished dies. $\times 150$.

$A$, Flat-back type; $B$, exit-cone type. diameters greater than 0.0012 -in., resort is made to mechanical enlargement on the polishing machine.

Cleaning.-When dies become filled with foreign matter the usual procedure is to clean them with a pointed piece of wood or with a fine bristle brush and a solvent such as alcohol or gasoline. These methods work well with large dies but often fail with small dies because the secondary cone and bearing are much smaller than the bristles of the brush.

In the Bureau's laboratory the dies are cleaned with the high-voltage spark produced by the apparatus shown in figure 3 . It is essential that the capacitor be removed from the circuit, figure 4 , for the cleaning operation, otherwise the spark will enlarge the die diameter about 0.002 in. in 1 or 2 seconds.

The die is placed with the orifice up on the brass block, $B$, and the sharpened electrode is lowered to within approximately $1 \mathrm{~mm}$ of the orifice. When about $40 \mathrm{v}$ are applied to the primary circuit, a spark will pass through the die cone from the electrode. An application of the spark for 2 to 3 seconds will usually remove the dirt. The spark may, however, pass around the die if the die is badly plugged. In this case the die is inverted, and the electrode is lowered into the primary cone. By thus shortening the path for the spark through the secondary cone, the die will be cleaned by reapplying the spark.

\section{Drilling Time}

The primary cone is drilled by the above procedure in about $3 \mathrm{hr}$, of which $1 / 2 \mathrm{hr}$ is required for electrical spotting and fore-drilling and the remainder for mechanical coning. The secondary cone is formed in $1 \frac{1}{4}$ to $2 \mathrm{hr}$, including the time required for a 30-minute drilling with $\mathrm{NaCl}$. Back relief is obtained with a 5-minute drilling with $\mathrm{NaCl}$. The total time required to cone and drill a die is therefore approximately $5 \mathrm{hr}$.

Considerable variation exists in the time required to finish dies. Those needing but a small amount of blending and polishing may be finished in 2 or less hours; others may require as many as $10 \mathrm{hr}$ to obtain a satisfactory finish. In general, $10 \mathrm{hr}$ is about the average time for drilling and finishing a 0.0006- to 0.0012-in. die.

The actual man-hours taken by the die maker to produce small dies will, however, be much 
less because all operations except the 30 minutes for high-voltage drilling of the primary cone and the 5 minutes for electrolytic drilling of the back relief may be performed in multiple. One operator can electrolytically drill 6 or more dies simultaneously or can attend 10 or more spindles on the coning and polishing machine for coning and finishing operations. The time required to drill and finish small dies on a production basis should not greatly exceed 2 man-hours.

Neither spotting or fore-drilling by the highvoltage method nor electrolytic drilling of the secondary cone requires special skill or long training of the operator. Most die makers have produced excellent dies after 4 or $5 \mathrm{hr}$ of instruction in the electrical methods by members of the Bureau's Interferometry Section.

\section{Quality of the Dies}

Cones produced by either high-voltage or electrolytic drilling give no evidence of added strain to the surrounding diamond when examined under polarized light, whereas the material underlying the facets and primary and exit cones shows severe strain and minute fractures when these elements are produced by bruting. Strain to a lesser degree results from mechanical drilling and, although its magnitude decreases with reduced load on the needle and size of diamond powder used, it is still present in mechanically drilled secondary cones. Frequent failure by chipping at the intersection of secondary and exit cones of dies so drilled is ascribed to weakening of the material by the mechanical treatment. Likewise, rapid wear of some dies at their initial size may be attributed to disruption of material underlying the working surfaces of the dies that has not been removed by sufficient polishing.

Operations that tend to injure the diamond are avoided whenever possible at the Bureau. Facets are cut on a flat rotating lap rather than by bruting, and care is taken to avoid excessive loads on the needle while coning the primary cone after electrical fore-drilling. Electrolytically drilled secondary cones are usually quite round, have no drilling rings and, consequently, can be rounded and give a high polish with grade 4 diamond powder. Back relief is obtained by electrolytic drilling. Examination of a large number of dies when coördinated with their wire-drawing records indicated that the finish given a die is of great importance. Therefore, careful attention is paid to the finish of electrically drilled dies. For these reasons, National Bureau of Standards dies should wear as well, particularly at their initial size, as the best mechanically produced dies.

The performance of a die at a given size is measured by the quantity of wire that it draws within a specified tolerance of size and quality of the wire. It depends upon many variables, including the composition of the wire, condition of the wire as it reaches the die, drawing rate, amount of reduction, and other less determinate conditions. After a die wears out-of-round or to a greater diameter than the tolerance permits, it is polished to the next larger size at which the manufacturer wishes to draw wire. This procedure is repeated until the diamond fails by fracture or is no longer usable as a die. Several wire manufacturers are coöperating with this Bureau to determine the performance of 50 National Bureau of Standards dies at their initial diameter and, progressively, through the range of larger diameters until failure occurs. Although the reports submitted thus far are rather meager, the data indicate that an equal or appreciably greater amount of wire is obtained with the National Bureau of Standards dies than is obtained under the same drawing conditions with mechanically drilled dies.

\section{Orientation of the Die Axis}

Attempts of previous investigators to establish a preferred orientation of the die axis with respect to the crystal axes of the diamond have been somewhat inconclusive. Bureau dies submitted to each of the wire manufacturers included those drilled perpendicular to octahedron, dodecahedron, and cube faces respectively. Test reports thus far received are not sufficiently extensive to indicate a definite superiority of performance for any of these three orientations. The diameter of dies drilled perpendicular to the dodecahedron, face enlarges more rapidly during the polishing operation than those drilled perpendicular to either cube or octahedron faces; it remains to be proved, however, that the rate of increase in diameter by polishing is a reliable accelerated test for comparing die performance.

\section{Procedure for Making Exit-Cone Dies}

Flat-back dies, see figure 1, B, and figure 14, A, were developed at the Bureau to eliminate failure 
by chipping of the diamond which usually occurs when the bearing intersects the drilled or bruted surface of the exit cone. Furthermore, unless the axis of the exit cone coincides with the axis of the secondary cone, the bearing will intersect the side of the exit cone giving a die that will produce curly wire. This is not true with plane back dies because the secondary cone axis will always be normal to the back surface.

It has been stated that the spherical exit cone gives greater strength to the die. Considering the large size of the exit sphere relative to the small size of the die orifice, the secondary cone for all practical purposes intersects a plane surface. In view of the low breaking strength of a 0.001-in. wire, the small force exerted on the diamond in drawing wire of this size will doubtless be absorbed by that portion of the diamond which is immediately adjacent to the die cone.

In making exit cone dies it is customary either to first drill primary and exit cones and then open by drilling the secondary cone, or to first drill primary and secondary cones and then open by drilling or bruting the exit cone. In either case fractures are almost certain to be produced around the orifice.

While the performance of plane back dies is excellent, most wire manufacturers conservatively prefer to purchase the customary exit cone type (see fig. 1, A, and fig. 14, B). The advantages of the electrical drilling methods, however, apply equally well to the production of this latter type. In this case, after the primary cone is completed, the exit sphere is drilled to within $0.006 \mathrm{in}$. of the apex of the primary cone. The secondary cone is then drilled electrolytically.
With either type of die it is imperative to produce a well polished relief or countersink of from 0.0005 to $0.001 \mathrm{in}$. in depth at the orifice to reduce chipping to a minimum.

\section{Conclusion}

Electrical drilling greatly reduces the production time for diamond wire-drawing dies less than 0.0015 in. in diameter. Most of the 100 or more hours required to drill and finish a $0.001 \mathrm{in}$. die by mechanical processes is spent in drilling the small secondary cone. This can be electrically drilled in from 1 to 2 hours. A further saving in time is effected when primary and exit cones are spotted and pilot-drilled electrically. As the necessary mechanical operations and the electrolytic drilling of the secondary cone can be performed in multiple, the labor required to drill and finish dies is reduced accordingly and does not greatly exceed 2 manhours a die. Service reports from wire manufacturers show that electrically drilled dies give excellent performance.

Equipment for electrical drilling is inexpensive and the drilling technic is simple, thereby making the work less tedious and eliminating the extreme skill required to drill small dies by mechanical methods.

A satisfying development of the present investigation is that domestic die makers are now able to produce economically an adequate supply of small diamond dies in the critical range of 0.0004 to 0.002 in. in diameter.

Washington, January 6, 1947. 